\title{
ORDEM DE PALAVRAS E EXPRESSÃO DA ÊNFASE EM PORTUGUÊS
}

\section{WORD ORDER AND EMPHASIS EXPRESSION IN PORTUGUESE}

\author{
Michel Gustavo Fontes* \\ UFMS
}

\author{
Kátia Roberta Rodrigues-Pinto** \\ UFMS
}

Resumo: Com base no aparato teórico-metodológico da Gramática Discursivo-Funcional (HENGEVELD; MACKENZIE, 2008), analisa-se a ordem de palavras como correlato formal de distinções pragmáticas próprias à interação entre falante e ouvinte. A intenção central é investigar a expressão de ênfase, no português, por meio da ordenação de constituintes. Para tanto, são cotejados dois objetos de estudo: (i) a ordem do constituinte interrogativo no interior da Interrogativa-Qu; e (ii) a ordem do item ainda em construções comparativas. Como resultados, este artigo defende que: (i) a ordem final do constituinte interrogativo na oração corresponde a um mecanismo de marcação de ênfase, direcionando a atenção do ouvinte para o conteúdo interrogado; (ii) já a ordem de ainda, no interior da construção comparativa, associa-se à expressão de dois diferentes tipos de ênfase: ênfase propriamente dita e ênfase graduadora.

Palavras-chave: Ordenação de constituintes. Ênfase. Gramática Discursivo-Funcional.

\begin{abstract}
Based on Functional Discourse Grammar model (Hengeveld; Mackenzie, 2008), this paper analyzes word order as a formal device for marking pragmatic distinctions. The aim is to investigate emphasis expression in Portuguese by means of word order. To do so, two objects of study are approached here: (i) the ordering of the interrogative constituent within Wh-Interrogatives; and (ii) the ordering of the item ainda ('still'/'yet'/'even') in comparative constructions. In relation to (i), this article reveals that the final order of the interrogative constituent in the sentence corresponds to an emphasis marking mechanism, in order to gain the addressee's attention to the questioned content. In relation to (ii), the positions of ainda are associated with the expression of two different types of emphasis: emphasis and degree emphasis.
\end{abstract}

Keywords: Word order. Emphasis. Functional Discourse Grammar.

\section{CONSIDERAÇÕES INICIAIS}

No interior da Linguística, o termo funcionalismo tem abrigado um conjunto bastante diverso de correntes teóricas que, embora se diferenciem quanto ao modo como concebem a

\footnotetext{
* Doutor em Estudos Linguísticos. Professor Adjunto na Universidade Federal de Mato Grosso do Sul, Três Lagoas, MS, Brasil. E-mail: michel.fontes@ufms.br.

** Mestranda em Letras (área de concentração: Estudos Linguísticos) na Universidade Federal de Mato Grosso do Sul, Três Lagoas, MS, Brasil. E-mail: katiarodriguespinto@gmail.com.
} 
organização gramatical de uma língua, compartilham de uma série de princípios (cf. BUTLER, 2003, p. 33), tais como:

(i) Visão de língua como instrumento de comunicação e de interação nos mais diversos contextos sociais;

(ii) Rejeição à abordagem autônoma da gramática, favorecendo explanações de natureza funcional, que tomam o sistema linguístico como co-determinado por fatores de ordem sociocultural, cognitiva, psicológica e diacrônica;

(iii) Recusa ao tratamento autônomo da sintaxe, valorizando a correlação entre forma (padrões morfossintáticos e/ou fonológicos) e função (propriedades de ordem semântico-pragmática) e, assim, tomando a sintaxe como meio de expressão de significados;

(iv) Objeção a uma concepção inatista e adaptacionista da aquisição de linguagem, seguindo um prisma mais sociocognitivo e construcionista.

Butler (2003) reconhece, no interior do funcionalismo linguístico, seis correntes teóricas: (i) o funcionalismo gerativo (generative functionalism, no inglês), um tipo mais periférico de funcionalismo representado nos trabalhos de Ellen Prince e S. Kuno; (ii) o funcionalismo holandês, representado pelos modelos de gramática funcional de Simon C. Dik (1997a; 1997b) e de Hengeveld e Mackenzie (2008); (iii) a Gramática de Papel e Referência, desenvolvida centralmente por Van Valin, junto a outros colaboradores; (iv) a Gramática Sistêmico-Funcional, associada principalmente ao trabalho de Halliday; (v) o funcionalismo americano, representado por um conjunto de trabalhos de linguistas que se concentram na região da Costa Oeste dos Estados Unidos, como Givón, Hopper e Thompson; (vi) a linguística cognitivo-funcional, que procura conjugar os pressupostos do funcionalismo (principalmente o de vertente americana) e da Linguística Cognitiva.

Este artigo, propondo um exercício de análise e de descrição funcionalista, volta sua atenção para um fenômeno morfossintático específico, a ordem de palavras, de modo a oferecer-lhe uma explanação que revele sua instrumentalidade e sua funcionalidade no interior da interação verbal. Especificamente, o objetivo é caracterizar o modo como a ordenação de constituintes se correlaciona à expressão de um significado pragmaticamente assentado, vinculado aos propósitos comunicativos do falante: a ênfase.

Para tanto, o artigo adota, como arcabouço teórico-metodológico, o modelo da Gramática Discursivo-Funcional (doravante GDF), de Hengeveld e Mackenzie (2008), e, revisando considerações e dados de trabalhos anteriores (cf. FONTES, 2012a; 2012b; 2016), seleciona dois objetos de análise, exemplificados em (1) e (2), que se caracterizam por certa flexibilidade em termos de disposição linear, o que é produtivo para os propósitos mais gerais deste artigo.

Em (1), têm-se ocorrências de Interrogativas-Qu: sentenças interrogativas diretas que, ao assinalarem o desconhecimento do falante em relação a um conteúdo específico, constituem-se de uma proforma interrogativa. Interessa a esta investigação a ordem assumida pelo constituinte interrogativo no interior da oração, já que, em português, ele pode se situar na posição inicial (cf. (1a)) ou na posição final (cf. (1b)). 
(1) a Olhe-se no espelho! $\boldsymbol{O}$ que você vê? Sinceramente. (leticiathompson.net)

b Estado - Você foi fazer o quêe? (19Or:Br:Intrv:ISP)

Em (2), são trazidas ocorrências de uso de ainda em construções comparativas de desigualdade. No interior desse tipo de construção, ainda pode alocar-se ao final do sintagma comparativo (cf. (2a)), ou à esquerda da palavra de grau mais, na posição inicial do sintagma comparativo (cf. (2b)).

a porque o indivíduo trazer panelas é: estranho - panelas usadas é mais estranho ainda - aí tem umas coisas assim (19Or:Br:LF:Recf)

b prossegue a identificação e desmobilização das tropas da UNITA, cuja reintegração é ainda mais difícil (19N:Pt:Expr)

Este artigo assume que essa aparente flexibilidade, em termos de ordenação, do constituinte interrogativo, no interior da oração interrogativa, e de ainda, no interior do sintagma comparativo, é determinada por questões de natureza pragmática. A intenção, aqui, é mapear os efeitos pragmáticos, especificamente em termos de marcação de ênfase, correlacionados às disposições assumidas por esses elementos linguísticos.

O material de análise para se proceder com tal investigação é composto de ocorrências do português atual, provenientes do Córpus do Português (DAVIES; FERREIRA, 2006), disponível online em https://www.corpusdoportugues.org/. O artigo se estrutura em cinco partes: a primeira apresenta sucintamente o arcabouço teórico que sustenta a investigação, a GDF; a segunda precisa a concepção de ênfase presente na GDF e aqui assumida para a condução da análise; a terceira trata da ordem de palavras na GDF; a quarta e a quinta apresentam os resultados de pesquisa, traçando uma explanação funcional em torno à ordem do constituinte interrogativo e do item ainda em construções comparativas. As considerações finais sistematizam a proposição mais central do artigo.

\section{A GRAMÁTICA DISCURSIVO-FUNCIONAL}

A GDF, enquanto modelo de gramática de orientação funcionalista, debruça-se sobre questões formalmente codificadas na língua (em termos de aspectos morfossintáticos e fonológicos), correlacionando-as, quando possível, a propriedades semântico-pragmáticas, próprias à formulação linguística. ${ }^{1}$ Além disso, a GDF tem forte influência tipológica em sua proposição, tentando fornecer as ferramentas necessárias para investigação e estudo da variabilidade existente entre as línguas.

Seguindo uma visão modular de gramática, a GDF corresponde, no interior de uma teoria mais geral da interação verbal, ao Componente Gramatical, ligado a outros três componentes não linguísticos: o Componente Conceitual, responsável por gerar as intenções comunicativas do falante, o Componente Contextual, que abarca informações próprias ao contexto (linguístico e/ou situacional) em que se dá a interação, e o Componente de Saída, que traduz os inputs do Componente Gramatical em material acústico, escrito e/ou simbólico.

\footnotetext{
${ }^{1}$ A GDF prima por estabelecer relações sistemáticas de alinhamento entre propriedades semântico-pragmáticas e padrões morfossintáticos, porém reconhece, também, que alguns fenômenos morfossintáticos são arbitrários, não decorrendo de qualquer motivação mais discursiva, como, em inglês, o uso da proforma it em sentenças como It is snowing, em que a presença do pronome é motivada por questões próprias à organização morfossintática da língua.
} 
Conforme demonstra a figura 1 abaixo, a GDF (ou o Componente Gramatical) está organizada em quatro níveis independentes, articulados entre si via relações de interface: os níveis Interpessoal e Representacional captam, respectivamente, questões pragmáticas e semânticas envolvidas na formulação de uma expressão linguística, e os níveis Morfossintático e Fonológico dão conta da codificação, que transforma o input proveniente da formulação em estruturas morfossintáticas e em padrões fonológicos, respectivamente. Toda a arquitetura da GDF parte de uma perspectiva descendente (top-down) de produção linguística, que começa com a intenção comunicativa dos usuários da língua gerada no interior do Componente Conceitual e que se desenvolve linguisticamente ao longo do Componente Gramatical, até chegar ao Componente de Saída.

Figura 1: Arquitetura geral da GDF (cf. HENGEVELD; MACKENZIE, 2012, p. 46)

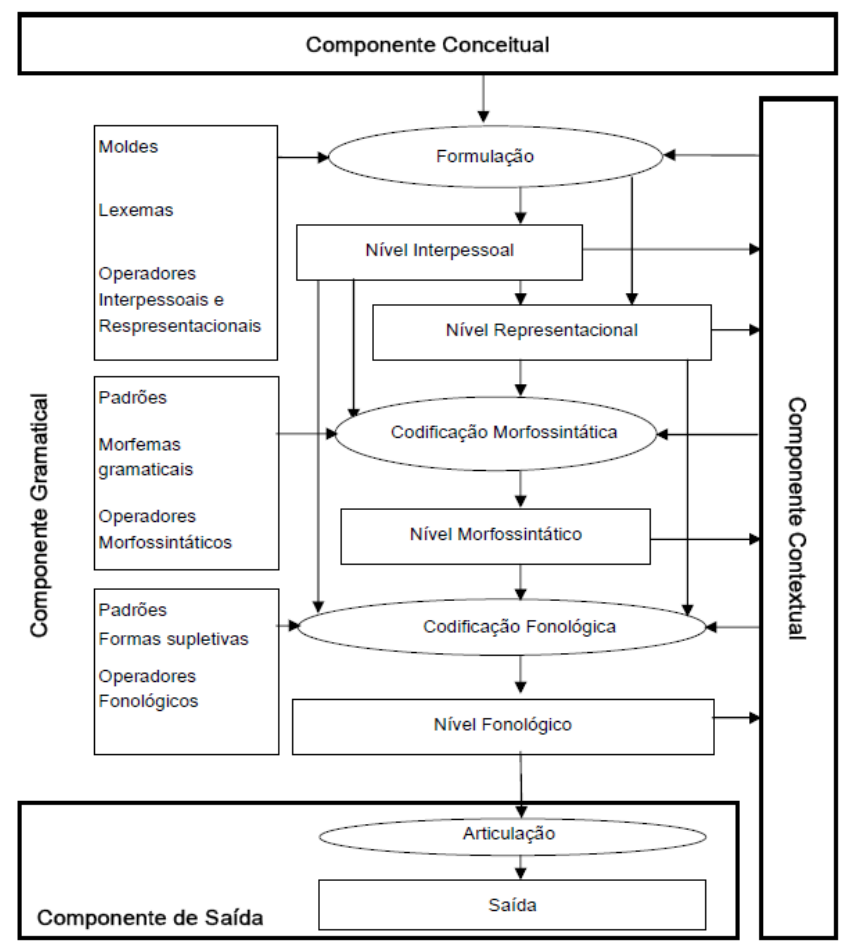

Cada um dos níveis que organizam a GDF está internamente estruturado em camadas hierarquicamente organizadas. Em (3), o esquema representa a organização mais geral dos níveis: $\mathrm{v}_{1}$ corresponde à camada relevante para a análise, que pode ser restringida por um núcleo ou por um modificador ( $\sigma$ ); a camada pode ainda ser especificada por um operador ( $\pi$ ) e conter uma função $(\Phi) .^{2}$

$$
\left(\pi \mathrm{v}_{1}:\left[\text { núcleo }\left(\mathrm{v}_{1}\right)_{\Phi}\right]:\left[\sigma\left(\mathrm{v}_{1}\right)_{\Phi}\right]\right)
$$

\footnotetext{
${ }^{2}$ Esses primitivos se diferenciam não só por sua funcionalidade, mas também por seu estatuto léxico-gramatical: enquanto núcleos e modificadores representam estratégias lexicais, operadores e funções representam estratégias gramaticais. Núcleos correspondem à peça de informação mais central para uma camada, enquanto modificadores são elementos restritores opcionais, que trazem alguma informação adicional para a camada sob análise. Por outro lado, operadores especificam algum valor semântico-pragmático aplicado à camada, e funções são relacionais, vinculando uma unidade a outras unidades da mesma camada.
} 
No Nível Interpessoal, são distinguidos os mecanismos formalmente codificados que refletem o papel de uma unidade linguística no interior da interação verbal, seja em termos retóricos (marcando o modo como o falante combina os componentes de seu discurso para atingir sua estratégia comunicativa e, assim, influenciar o ouvinte), seja em termos pragmáticos (modelando a mensagem do falante tendo em vista suas expectativas em relação ao estado mental do ouvinte). Em (4), estão dispostas as camadas que ordenam internamente o Nível Interpessoal: o Movimento (M), camada hierarquicamente superior dentro do nível, deve conter ao menos um Ato Discursivo (A); o Ato Discursivo, por sua vez, pode conter uma Ilocução (F), posições para os Participantes $(\mathrm{P})$, no caso Falante $\left(\left(\mathrm{P}_{1}\right)_{\mathrm{S}}\right)$ e Ouvinte $\left(\left(\mathrm{P}_{2}\right)_{\mathrm{A}}\right)$, e um Conteúdo Comunicado (C), que se estrutura a partir de um número de Subatos de Referência (R) ou de Atribuição (T).

$$
\begin{aligned}
& \left(\mathrm{M}_{1}:\left[\left(\mathrm{A}_{1}:\left[\left(\mathrm{F}_{1}\right)\left(\mathrm{P}_{1}\right)_{\mathrm{S}}\left(\mathrm{P}_{2}\right)_{\mathrm{A}}\left(\mathrm{C}_{1}:\left[\left(\mathrm{T}_{1}\right)_{\{\Phi\}} \ldots\left(\mathrm{T}_{1+\mathrm{N}}\right)_{\{\Phi\}}\left(\mathrm{R}_{1}\right)_{\{\Phi\}}\right]\left(\mathrm{C}_{1}\right)_{\{\Phi\}}\right)\right]\left(\mathrm{A}_{1}\right) \ldots\right.\right.\right. \\
& \left.\left.\left(\mathrm{A}_{1+\mathrm{N}}\right)_{\{\Phi\}}\right]\left(\mathrm{M}_{1}\right)\right)
\end{aligned}
$$

No Nível Representacional, são abrigadas questões denotativas das expressões linguísticas, isto é, as representações semânticas das unidades linguísticas. A representação em (5) traz as suas camadas, distinguidas em termos ontológicos, isto é, em termos de entidades (ou categorias) semânticas que elas designam: Conteúdos Proposicionais (p); Episódios (ep); Estados-de-coisas (e), Propriedades Configuracionais ( $\mathrm{f}^{\mathrm{c}}$ ) e Propriedades Lexicais (f). Outras categorias podem ainda ser distinguidas, como Indivíduo (x), Locação (l), Tempo (t), Modo (m), Razão (r) e Qualidade (q).

$$
\begin{aligned}
& \left(\mathrm{p}_{1}:\left[\left(\mathrm{ep}_{1}:\left[\left(\mathrm{e}_{1}:\left[\left(\mathrm{f}^{\mathrm{c}}\right):\left[\left(\mathrm{f}_{1}\right)^{\mathrm{n}}\left(\mathrm{x}_{1}\right)_{\Phi} \ldots\left(\mathrm{x}_{1+\mathrm{n}}\right)_{\Phi}\right]\left(\mathrm{f}^{\mathrm{c}}{ }_{1}\right)\right) \ldots\left(\mathrm{f}^{\mathrm{c}}{ }_{1+\mathrm{n}}\right)\left(\mathrm{e}_{1}\right)_{\Phi}\right]\right) \ldots\left(\mathrm{e}_{1+\mathrm{n}}\right)_{\{\Phi\}}\right]\left(\mathrm{ep}_{1}\right)\right) \ldots\right. \\
& \left.\left.\left(\mathrm{ep}_{1+\mathrm{n}}\right)_{\{\Phi\}}\right]\left(\mathrm{p}_{1}\right)\right)
\end{aligned}
$$

A codificação do input proveniente dos níveis Interpessoal e Representacional fica a cargo dos níveis Morfossintático e Fonológico: aquele amalgama esse input em unidades e padrões analisáveis em termos morfossintáticos, e este converte o material dos níveis superiores num construto fonológico. Em (6), demonstra-se a estruturação interna desse nível, cuja camada hierarquicamente superior é a Expressão Linguística (Le), que abriga qualquer conjunto de pelo menos uma unidade morfossintática, sendo elas: Orações (Cl), Sintagmas (Xp) ou Palavras $(\mathrm{Xw})$. Os tipos de Sintagmas e de Palavras variam conforme seu núcleo.

$$
\left.\left(\mathrm{Le}_{1}:\left[\mathrm{Cl}_{1}:\left[(\mathrm{Xw})\left(\mathrm{Xp}_{1}:\left[(\mathrm{Xw})\left(\mathrm{Xp}_{2}\right)\left(\mathrm{Cl}_{2}\right)\right]\left(\mathrm{Xp}_{1}\right)\right)\left(\mathrm{Cl}_{3}\right)\right]\left(\mathrm{Cl}_{1}\right)\right)\right]\left(\mathrm{Le}_{1}\right)\right)
$$

Para os propósitos deste artigo, restringe-se a análise centralmente no alinhamento entre os níveis Interpessoal e Morfossintático (alinhamento interpessoal), pois o que se busca aqui demonstrar é que a operação pragmática de ênfase, própria ao Nível Interpessoal, pode ser capturada formalmente, no Nível Morfossintático, por meio de padrões específicos de ordenação.

\section{ÊNFASE NA GDF}

Os funcionalistas, de modo geral, têm adotado uma visão bastante ampla em torno à categoria pragmática foco. Isso se ilustra, por exemplo, em Herring e Paolillo (1995, p. 163), que consideram como informação focal aquela para a qual o falante, ou escrevente, deseja assinalar especial saliência. Komen (2013, p. 33), dialogando com tal visão, assume que foco é a parte da sentença que deve ser entendida, pelo ouvinte, como mais proeminente ou saliente, já 
que ou corresponde a uma informação nova, ou contrasta com uma informação pressuposta, ou trata-se de uma informação imprevisível, não recuperável ou de grande interesse comunicativo.

Hengeveld e Mackenzie (2008) optam por seguir a primeira via proposta por Hannay (1983). Ao definir o Nível Interpessoal da GDF, os autores reconhecem que, na interação entre falante e ouvinte, pode-se empregar uma série de estratégias pragmáticas, que determinam o modo como o falante constrói e modela sua mensagem tendo em vista suas expectativas em relação à informação pragmática do ouvinte. Assim, o falante pode optar por selecionar certa informação como ponto de partida de sua mensagem, ou assinalar a novidade de uma informação a ser trazida para a interação, ou ainda salientar ou colocar em proeminência determinada informação.

Entre essas estratégias pragmáticas, Hengeveld e Mackenzie (2008) distinguem funções pragmáticas, como Tópico, Foco e Contraste, da operação de ênfase. ${ }^{3}$ A função pragmática Foco, especificamente, e a ênfase se diferenciam nos seguintes termos: enquanto a primeira assinala a seleção estratégica operada pelo Falante de informação nova para preencher uma lacuna na informação pragmática do Ouvinte ou para corrigir uma informação do Ouvinte, a segunda corresponde a um mecanismo de intensificação ou de saliência, ou seja, um recurso linguístico que serve ao propósito comunicativo do falante em destacar ou colocar em proeminência uma determinada (peça de) informação, chamando a atenção do ouvinte para ela.

Assim, a ênfase, no interior do modelo da GDF, corresponde, genericamente, a uma categoria pragmática de intensificação ou de reforço, podendo ser captada por modificadores e/ou operadores e aplicando-se a diferentes camadas do Nível Interpessoal.

A ênfase pode decorrer da estratégia comunicativa do falante em intensificar o Ato Discursivo por ele proferido. Em (7), o modificador dammit, no inglês, intensifica/enfatiza o Ato Discursivo como um todo, o que também se aplica a (8), por meio da construção iniciada pela partícula gramatical que. Em ambos os casos, observa-se que o modificador dammit e o operador que se combinam a qualquer tipo de Ilocução, o que indica seu escopo sobre todo o Ato Discursivo.
a Answer me dammit.
b Did you do it or not dammit?
c I want to go home dammit.
d Let's go dammit. (HENGEVELD; MACKENZIE, 2008, p. 64-65)

(8) a ¡Que no me gusta nada esa película!

b ¿'QQue si vienes mañana!?

c ¡Que no te marches mañana! (HENGEVELD; MACKENZIE, 2008, p. 67)

A ênfase pode também se aplicar a unidades mais internas ao Ato Discursivo. Por exemplo, na camada da Ilocução, Hengeveld e Mackenzie (2008) distinguem um operador enfático,

\footnotetext{
${ }^{3} \mathrm{Na}$ GDF, funções pragmáticas refletem o estatuto comunicativo de unidades linguísticas em termos de saliência ou de relevância para o andamento do discurso. A função Tópico é atribuída ao Subato que assinala o modo como o Conteúdo Comunicado se relaciona ao registro construído gradualmente no Componente Contextual. Essa definição pressupõe a atribuição de Tópico à informação dada, havendo assim uma correlação default entre Tópico e informação dada. Já a função Contraste assinala o desejo do falante em contrastar as diferenças entre Conteúdos Comunicados ou entre um Conteúdo Comunicado e informações disponíveis contextualmente.
} 
que afeta diretamente a força ilocucionária do Ato. É o caso da partícula dan em holandês (cf. (9)), cujo uso, conforme Vismans (1994, p. 62, apud HENGEVELD; MACKENZIE, 2008, p. 83), restringe-se a Atos Imperativos, o que sinaliza que a ênfase por ele expressa se aplica sobre a Ilocução Imperativa.

Doe je werk dan!
fazer seu trabalho ENF
'vamos lá, faça seu trabalho!'

Por outro lado, Hengeveld e Mackenzie (2008) também preveem operadores e modificadores que são responsáveis por enfatizar, ou salientar, o conteúdo comunicativo evocado por um Ato. Em (10), o modificador really intensifica o Conteúdo Comunicado do Ato Discursivo. Segundo os autores, pode-se notar o escopo de really sobre o Conteúdo Comunicado por sua ordenação mais interna à oração ${ }^{4}$ e por se combinar com outros tipos de modificadores enfáticos, como em (10c).

(10) a I really don't like you.

b Do you really want to hurt me?

c I really don't like you dammit.

(HENGEVELD; MACKENZIE, 2008, p. 67)

A contrapartida gramatical do modificador de ênfase na camada do Conteúdo Comunicado é o operador de ênfase que, segundo Hengeveld e Mackenzie (2008), tem origem com a gramaticalização de construções clivadas. O padrão de clivagem (CLEFT) em (11), do Galego escocês, serve para enfatizar o Conteúdo Comunicado do Ato ali proferido.

(11) ' $S$ ann $\boldsymbol{a}$ dh'fheumas tu rud beag de dh'eòlas ciùil CLEFT must/need 2.SG thing little of knowledge music. GEN It's just that you must have some knowledge of music.

A ênfase, por fim, pode se aplicar a Subatos que compõem o Conteúdo Comunicado. Em (12), por exemplo, o modificar really sinaliza um compromisso enfático, por parte do falante, ao atribuir a propriedade nice ao indivíduo example. Assim, o escopo de really está sobre o Subato Atributivo nice.

(12) a really nice example (HENGEVELD; MACKENZIE, 2008, p. 67)

Já na camada do Subato Referencial, Hengeveld e Mackenzie (2008) defendem que a ordem pode ser mobilizada para a expressão de ênfase. Em (13a-b), as duas respostas se diferenciam, em termos formais, pela ocorrência do sintagma $a$ whole week em posição inicial em (13b), o que se correlaciona à aplicação de ênfase ao Subato Referencial. Em ambas as sentenças, o constituinte tem o mesmo estatuto informacional (trata-se de informação nova), mas, em (13b), encontra-se mais saliente e destacado por meio de sua ordenação ao início da oração.

\footnotetext{
${ }^{4}$ Para Hengeveld e Mackenzie (2008), operadores e modificadores do Ato Discursivo assumem posições mais periféricas na Oração, enquanto operadores e modificadores do Conteúdo Comunicado se dispõem mais internamente na Oração.
} 

Did you get a day off?

a A day off? The boss gave me a whole week.

b A day off? A whole week the boss gave me.

(HENGEVELD; MACKENZIE, 2008, p. 123)

Em suma, podemos ver que, para a GDF, a expressão da ênfase pode se dar por meios lexicais (modificadores enfáticos) ou por meios gramaticais (operadores enfáticos). Além disso, a depender da camada que modifica ou em que opera, eles podem ter diferentes matizes pragmáticos: reforço, comprometimento, realce, chamada de atenção, etc. O exemplo em (13) é o que motiva, centralmente, a proposição de nossa investigação: de que modo é possível correlacionar a ordem de palavras a efeitos enfáticos decorrentes da necessidade comunicativa do falante ao interagir com o ouvinte?

\section{A ORDEM DE PALAVRAS NA GDF}

Abordar, sob perspectiva funcionalista, a ordem de palavras significa compreender que o fenômeno não se dá de modo aleatório, mas é motivado por questões funcionais e cognitivas, ligadas ao papel comunicativo e interativo que cumprem as línguas. Assim, acredita-se que a ordem de palavras, dentro de uma expressão linguística, esteja fortemente atrelada às necessidades comunicativas dos usuários da língua, como bem afirma Downing (1995, p. 9):

as informações veiculadas pelas variações da ordem das palavras não se limitam às proposicionais [...]. As escolhas por ordem das palavras também podem ser ditadas pela necessidade do falante ou do escrevente em estabelecer uma postura social ou afetiva, em criar estruturas no nível do texto a partir de recursos do nível da sentença e em se comunicar de uma maneira que seja perfeitamente compatível com as capacidades cognitivas do receptor do texto. ${ }^{5}$

A autora estabelece, em sua afirmação, três fatores mais gerais relevantes para se mapear as motivações para a ordenação de constituintes:

(i) A marcação de afeto, casos em que a ordem de palavras serve, de alguma maneira, para marcar alguma postura mais atenta ou afetiva do falante em relação ao ouvinte;

(ii) A criação de estrutura textual, que diz respeito ao modo pelo qual, a partir da ordenação de palavras, pode-se desenhar o arranjo textual e indicar o papel dos constituintes da sentença em relação ao todo textual;

(iii) A facilidade de processamento linguístico, estando por trás de muitos tipos de fenômenos linguísticos que parecem acomodar os pontos fortes e fracos de nossos sistemas cognitivos. Por exemplo, costuma-se limitar, em uma sentença, o número de informações novas (geralmente uma) por proposição/sentença, devido à dificuldade de se processar grandes quantidades de informações novas.

\footnotetext{
${ }^{5}$ No original: “The information carried by word order variations is not confined to the propositional [...]. Word order choices may also be dictated by the need of the speaker or writer to establish a social or affective stance, to create text level structures from sentence-level resources, and to communicate in a way which is optimally matched to the text receiver's cognitive capacities" (DOWNING, 1995, p. 9).
} 
A GDF, seguindo uma orientação funcionalista, aborda a ordenação de constituinte como fenômeno morfossintático funcionalmente motivado. No interior do Nível Morfossintático, são previstos três princípios funcionais para governar as relações de alinhamento entre padrões de disposição linear e determinações semântico-pragmáticas:

(i) O princípio de iconicidade, segundo o qual uma expressão linguística tende a refletir a ordem natural dos elementos no mundo extralinguístico;

(ii) O princípio de integridade de domínio, segundo o qual elementos de um mesmo domínio (ou, na GDF, de um mesmo nível ou camada) tendem a permanecer juntos (ou justapostos) na expressão linguística. Por exemplo, modificadores tendem a se posicionar próximos aos núcleos que modificam, assim como funções e operadores tendem a ser realizados por expressões que se encontram próximas às unidades morfossintáticas a que se aplicam, e

(iii) O princípio de estabilidade funcional, também denominado de preservação das relações de escopo, segundo o qual elementos de mesma especificação, interpessoal ou representacional, devem ser posicionados na mesma posição relativa a outras categorias; por exemplo, em algumas línguas, a ordenação dos constituintes que carregam a função Foco é determinada pela posição com relação ao verbo.

Além disso, Hengeveld e Mackenzie (2008) reconhecem que vários fatores podem interferir na linearização dos constituintes: do Nível Interpessoal, as principais motivações estão associadas à atribuição de funções pragmáticas e à referenciação; fatores relacionados às funções semânticas e à designação partem do Nível Representacional; e, por fim, há determinações de ordem morfossintática, do Nível Morfossintático, como as funções sintáticas e a complexidade estrutural dos itens linguísticos.

A ordenação de constituintes, no interior do Nível Morfossintático, pode se dar em três camadas distintas: Expressão Linguística, Oração e Sintagma. Interessa, para este trabalho, os padrões de ordenação possíveis nas camadas da Oração e do Sintagma.

No interior da Oração, são distinguidas quatro posições absolutas: a posição inicial $\left(\mathrm{P}^{\mathrm{I}}\right)$, uma segunda posição, posterior à inicial $\left(\mathrm{P}^{2}\right)$, a posição medial $\left(\mathrm{P}^{\mathrm{M}}\right)$ e a posição final $\left(\mathrm{P}^{\mathrm{F}}\right)$. Além dessas, as línguas podem fazer uso de posições relativas às absolutas, conforme demonstra a figura 2. Em síntese, a GDF prevê que, na Oração, as línguas podem fazer uso da posição inicial $\left(\mathrm{P}^{\mathrm{I}}\right)$ e suas expansões para a direita $\left(\mathrm{P}^{\mathrm{I}+1}, \mathrm{P}^{\mathrm{I}+\mathrm{n}}\right)$, da posição $\mathrm{P}^{2}$ e de suas expansões à esquerda $\left(\mathrm{P}^{2+1} ; \mathrm{P}^{2+\mathrm{n}}\right)$, da posição final $\left(\mathrm{P}^{\mathrm{F}}\right)$ e suas expansões para a esquerda $\left(\mathrm{P}^{\mathrm{F}-1}, \mathrm{P}^{\mathrm{F}-\mathrm{n}}\right)$ e da posição medial $\left(\mathrm{P}^{\mathrm{M}}\right)$ e de suas expansões para a direita $\left(\mathrm{P}^{\mathrm{M}+1}, \mathrm{P}^{\mathrm{M}+\mathrm{n}}\right)$, para a esquerda $\left(\mathrm{P}^{\mathrm{M}-1}, \mathrm{P}^{\mathrm{M}-\mathrm{n}}\right)$ ou para ambas as direções ( $\left.\mathrm{P}^{\mathrm{M}-\mathrm{N}} ; \mathrm{P}^{\mathrm{M}-1} ; \mathrm{P}^{\mathrm{M}} ; \mathrm{P}^{\mathrm{M}+1} ; \mathrm{P}^{\mathrm{M}+\mathrm{N}}\right)$.

Figura 2: Posições absolutas e relativas da Oração (cf. HENGEVELD; MACKENZIE, 2008)

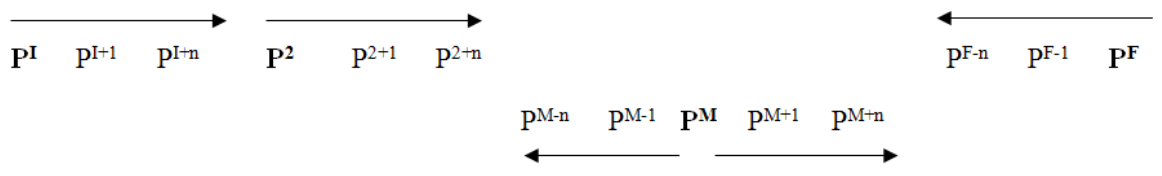

Para Pezatti (2014), em português, o padrão de ordenação de constituintes da Oração se vale de três posições absolutas $\left(\mathrm{P}^{\mathrm{I}}, \mathrm{P}^{\mathrm{M}}\right.$ e $\left.\mathrm{P}^{\mathrm{F}}\right)$ e de suas posições relativas, sendo que o predicado 
da Oração sempre se aloca na posição absoluta $\mathrm{P}^{\mathrm{M}}$. Segundo a autora, as posições $\mathrm{P}^{\mathrm{I}}$ e $\mathrm{P}^{\mathrm{F}}$ são reservadas para constituintes hierárquicos, e a posição $\mathrm{P}^{\mathrm{M}}$ abriga constituintes não hierárquicos. Uma questão importante, assinalada pela autora, é que constituintes hierárquicos (como modificadores, operadores e funções dos níveis Interpessoal e Representacional), sob o domínio da ordenação hierárquica, devem ser posicionados centripetamente, isto é, começando pelas margens da Oração e dirigindo-se para o centro. Além disso, as margens oracionais abrigam constituintes pragmática ou psicologicamente mais salientes.

Para o português, a autora (PEZATTI, 2014, p. 131) propõe três princípios de natureza pragmática, semântica e morfossintática subjacentes à ordem das palavras: (i) constituintes marcados pragmaticamente como Tópico ou Foco têm prioridade na alocação em $\mathrm{P}^{\mathrm{I}}$ ou $\mathrm{P}^{\mathrm{F}}$ sobre constituintes de natureza mais semântica; (ii) modificadores e operadores representacionais assumem as posições $\mathrm{P}^{\mathrm{I}}$ e $\mathrm{P}^{\mathrm{F}}$, obedecendo às suas relações de escopo; e (iii) se nenhuma dessas duas restrições se aplicar, a ordem dos constituintes se determina pela complexidade formal.

No interior do Sintagma, assim como ocorre na Oração, podem ser distinguidas três posições absolutas, $\mathrm{P}^{\mathrm{I}}, \mathrm{P}^{\mathrm{M}}$ e $\mathrm{P}^{\mathrm{F}}$, e posições relativas a essas: (i) expansões à direita de $\mathrm{P}^{\mathrm{I}}$, como $\mathrm{P}^{\mathrm{I}+1}, \mathrm{P}^{\mathrm{I+n}}$; (ii) expansões à esquerda de $\mathrm{P}^{\mathrm{F}}$, como $\mathrm{P}^{\mathrm{F}-1}, \mathrm{P}^{\mathrm{F}-\mathrm{n}}$; e (iii) expansões à direita ou à esquerda de $\mathrm{P}^{\mathrm{M}}$, como $\mathrm{P}^{\mathrm{M}-1}, \mathrm{P}^{\mathrm{M}-\mathrm{n}}$ e $\mathrm{P}^{\mathrm{M}+1}, \mathrm{P}^{\mathrm{M}+\mathrm{n}}$. A disposição linear de constituintes do Sintagma, de acordo com Hengeveld e Mackenzie (2008), obedece aos mesmos direcionamentos hierárquicos e configuracionais da Oração.

Para encerrar esta seção e dar sequência à exposição da análise, é central, para este trabalho, a ideia de que a ordenação de constituintes, questão formal própria ao Nível Morfossintático, reflete a organização das unidades e das propriedades dos níveis Interpessoal e Representacional.

\section{A ORDENAÇÃO DO CONSTITUINTE INTERROGATIVO}

Esta seção volta sua atenção para a ordem do constituinte interrogativo em InterrogativasQu diretas. Para atender ao seu objetivo central, a discussão aqui se restringe a casos de Interrogativas-Qu em que o constituinte interrogativo representa o segundo argumento de verbos transitivos e é codificado pela proforma (ou pronome) o que/o quê. ${ }^{6}$

No Nível Interpessoal, Interrogativas-Qu diretas correspondem a um Ato Discursivo com Ilocução Interrogativa (INT), e o constituinte interrogativo representa um Subato Referencial (R) ao qual se pode atribuir, a depender da função discursiva subjacente ao uso da Interrogativa-Qu, três diferentes combinações do operador de identificabilidade: (i) (+id, -s R) para as perguntas típicas (cf. (14)); (ii) (-id, +s R) para as perguntas retóricas (cf. (15)) e (iii) (-id, -s R) para as perguntas meditativas (cf. (16)). ${ }^{7}$

\footnotetext{
${ }^{6}$ Esta opção se dá devidos aos limites próprios de um artigo científico desta natureza. Acredita-se, conforme já apontado em outros trabalhos (FONTES, 2012a; 2012b), que as distinções aqui apresentadas também se aplicam sistematicamente a Interrogativas-Qu com outros constituintes interrogativos, como que, como, onde, etc.

${ }^{7}$ Hengeveld e Mackenzie (2008) preveem que, a um determinado referente (ou Subato Referencial) evocado na interação, podem ser aplicados operadores de identificabilidade e de especificidade: o primeiro diz respeito ao quanto o falante assume o referente como identificável (+id) ou não (-id) para o falante; o segundo, por sua vez, relaciona-se ao quanto o falante assume que um referente lhe é conhecido/específico (+s) ou não (-s). A partir desses operadores, a GDF prevê quatro combinações possíveis para um Subato Referencial: (i) (+id, +s R), (ii) (+id, -s R), (iii) (-id, +s R) e (iv) (-id, -s R).
} 
Perguntas típicas (cf. (14)) funcionam como pedidos de informação, isto é, são casos em que o falante assume seu desconhecimento em relação a uma informação e direciona seu questionamento ao ouvinte, quem, conforme sua pressuposição, detém tal informação. Assim, no Nível Interpessoal, o constituinte interrogativo figura como um Subato Referencial marcado pelo operador (+id, -s R): o falante, que desconhece um determinado referente (-s), assume que o ouvinte possa identificá-lo (+id).

(14) a JC - O que você faz nesse canal e há quanto tempo está lá? (19Or:Br:Intrv:Cid) NI: $\left(\mathrm{A}_{1}\right.$ : [( $\left.\mathrm{F}_{1}: \operatorname{INT}\left(\mathrm{F}_{1}\right)\right)\left(\mathrm{P}_{1}\right)_{\mathrm{S}}\left(\mathrm{P}_{2}\right)_{\mathrm{A}}\left(\mathrm{C}_{1}:\left[\left(+\mathbf{i d},-\mathbf{s} \mathbf{R}_{1}:\right.\right.\right.$ o que $\left.\left(\mathbf{R}_{1}\right)_{\mathrm{Foc}}\right)\left(\mathrm{R}_{2}:-\mathrm{S},+\mathrm{A}\left(\mathrm{R}_{2}\right)_{\mathrm{Top}}\right)$ $\left(\mathrm{T}_{1}\right.$ : faz $\left.\left(\mathrm{T}_{1}\right)\right)\left(\mathrm{R}_{3}\right.$ : nesse canal $\left.\left.\left.\left.\left(\mathrm{R}_{3}\right)\right)\right]\left(\mathrm{C}_{1}\right)\right]\left(\mathrm{A}_{1}\right)\right)$

NM: $\left(\mathrm{Cl}_{1}\right.$ : [( $\mathbf{N p}_{1}$ : o que $\left.\left(\mathbf{N p}_{1}\right)\right)\left(\mathrm{Np}_{2}\right.$ : você $\left.\left(\mathrm{Np}_{2}\right)\right)\left(\mathrm{Vp}_{1}\right.$ : faz $\left.\left(\mathrm{Vp}_{1}\right)\right)$ (Adpp ${ }_{1}$ : nesse canal $\left.\left.\left.\left(\mathrm{Adpp}_{1}\right)\right)\right]\left(\mathrm{Cl}_{1}\right)\right)$

\begin{tabular}{|c|c|c|c|}
\hline $\mathbf{P}^{\mathrm{I}}$ & $\mathrm{P}^{\mathrm{I}+1}$ & $\mathrm{P}^{\mathrm{M}}$ & $\mathrm{P}^{\mathrm{F}}$ \\
\hline o que & você & faz & nesse canal \\
\hline
\end{tabular}

b Ele monopolizou o cardápio, chamou o garçom e disse: -Eu quero um Chopp, você vai querer o quê? (amelhordasintencoes.wordpress.com)

NI: $\left(\mathrm{A}_{1}\right.$ : $\left[\left(\mathrm{F}_{1}: \mathrm{INT}\left(\mathrm{F}_{1}\right)\right)\left(\mathrm{P}_{1}\right)_{\mathrm{S}}\left(\mathrm{P}_{2}\right)_{\mathrm{A}}\left(\mathrm{C}_{1}:\left[\left(\mathrm{R}_{1}:-\mathrm{S},+\mathrm{A}\left(\mathrm{R}_{1}\right)_{\text {Top }}\right)\left(\mathrm{T}_{1}\right.\right.\right.\right.$ : vai querer $\left.\left(\mathrm{T}_{1}\right)\right)($ emph +id, -s $\mathbf{R}_{2}$ : o quê $\left.\left.\left.\left.\left(\mathbf{R}_{2}\right)_{\mathrm{Foc}}\right)\right]\left(\mathrm{C}_{1}\right)\right]\left(\mathrm{A}_{1}\right)\right)$

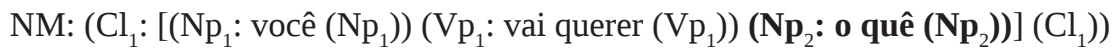

\begin{tabular}{|c|c|c|}
\hline $\mathrm{P}^{\mathrm{I}}$ & $\mathrm{P}^{\mathrm{M}}$ & $\mathbf{P}^{\mathrm{F}}$ \\
\hline você & vai querer & o quê? \\
\hline
\end{tabular}

Em (14a), o falante busca, junto ao ouvinte, uma resposta, buscando sanar sua dúvida ou desinformação em relação a que o ouvinte faz no canal. Já em (14b), após declarar o seu pedido, o falante se direciona a seu interlocutor na tentativa de obter a informação de qual será o pedido. Assim, nas ocorrências em (14), o falante assume seu desconhecimento sobre uma informação (-s), e a pergunta por ele colocada assinala seu desejo de que o ouvinte, quem, para ele, detém tal informação ausente (+id), forneça-a.

Já perguntas retóricas (cf. (15)) funcionam como estratégia argumentativa do falante para transmitir e/ou adicionar uma nova informação à consciência do ouvinte, isto é, são casos em que o falante não desconhece o referente interrogado $(+s)$, mas, pressupondo o desconhecimento do ouvinte (-id), vale-se da interrogativa-Qu como maneira de agir sobre a informação pragmática do ouvinte. Assim, no Nível Interpessoal, o constituinte interrogativo figura como um Subato Referencial marcado pelo operador (-id, +s R).

(15) a Temos todos as variáveis econômicas para nos desenvolver: recursos naturais, capital e mão de obra, o que falta? Educação! (altino.blogspot.com)

NI: $\left(\mathrm{A}_{1}\right.$ : [( $\mathrm{F}_{1}$ : INT $\left.\left(\mathrm{F}_{1}\right)\right)\left(\mathrm{P}_{1}\right)_{\mathrm{S}}\left(\mathrm{P}_{2}\right)_{\mathrm{A}}\left(\mathrm{C}_{1}\right.$ : [(-id, +s $\mathbf{R}_{1}$ : o que $\left.\left(\mathbf{R}_{1}\right)_{\mathrm{Foc}}\right)\left(\mathrm{T}_{1}\right.$ : falta $\left.\left.\left.\left(\mathrm{T}_{1}\right)\right)\right]\left(\mathrm{C}_{1}\right)\right]$ $\left.\left(\mathrm{A}_{1}\right)\right)$

NM: $\left(\mathrm{Cl}_{1}\right.$ : [(Np $\mathbf{p}_{1}$ : o que $\left.\left(\mathbf{N p}_{1}\right)\right)\left(\mathrm{Vp}_{1}\right.$ : falta $\left.\left.\left.\left(\mathrm{Vp}_{1}\right)\right)\right]\left(\mathrm{Cl}_{1}\right)\right)$

\begin{tabular}{|c|c|}
\hline $\mathbf{P}^{\mathrm{I}}$ & $\mathrm{P}^{\mathrm{M}}$ \\
\hline o que & falta? \\
\hline
\end{tabular}


b se nós observarmos na história da humanidade - os diversos sistemas filosóficos nós vamos verificar o quê? - que - essa história - que é a história do homem e do pensar humano - nós vamos encontrar um número infinito de soluções - divisões de mundo (19Or:Br:LF:Recf)

NI: $\left(\mathrm{A}_{1}\right.$ : $\left[\left(\mathrm{F}_{1}\right.\right.$ : INT $\left.\left(\mathrm{F}_{1}\right)\right)\left(\mathrm{P}_{1}\right)_{\mathrm{S}}\left(\mathrm{P}_{2}\right)_{\mathrm{A}}\left(\mathrm{C}_{1}:\left[\left(\mathrm{m} \mathrm{R}_{1}:+\mathrm{S},-\mathrm{A}\left(\mathrm{R}_{1}\right)_{\mathrm{Top}}\right)\left(\mathrm{T}_{1}\right.\right.\right.$ : vamos verificar $\left(\mathrm{T}_{1}\right)$ ) (emph +id, -s $\mathbf{R}_{2}: \mathbf{o}$ quê $\left.\left.\left.\left(\mathbf{R}_{2}\right)_{\mathrm{Foc}}\right)\right]\left(\mathrm{C}_{1}\right)\right]\left(\mathrm{A}_{1}\right)$ )

NM: $\left(\mathrm{Cl}_{1}\right.$ : [( $\mathrm{Np}_{1}$ : nós $\left.\left(\mathrm{Np}_{1}\right)\right)\left(\mathrm{Vp}_{1}\right.$ : vamos verificar $\left.\left(\mathrm{Vp}_{1}\right)\right)\left(\mathbf{N p}_{2}\right.$ : o quê $\left.\left.\left.\left(\mathbf{N p}_{2}\right)\right)\right]\left(\mathrm{Cl}_{1}\right)\right)$

\begin{tabular}{|c|c|c|}
\hline $\mathrm{P}^{\mathrm{I}}$ & $\mathrm{P}^{\mathrm{M}}$ & $\mathbf{P}^{\mathrm{F}}$ \\
\hline nós & vamos verificar & o quê? \\
\hline
\end{tabular}

Em (15a), ao tratar de variáveis econômicas para o desenvolvimento, o falante coloca uma pergunta para, de certa forma, salientar a introdução de uma nova informação, a de que falta educação; já em (15b), ao desenvolver a temática de história da humanidade, o falante suspende seu raciocínio e introduz a pergunta, para a qual dá uma resposta na sequência, o que configura como recurso retórico para sequenciar o discurso. Assim, em (15), o Falante não assume desconhecer a informação sob interrogação (+s), mas acredita que não está disponível para seu ouvinte (-id); a pergunta, então, funciona como estratégia de gerenciamento da interação e do fluxo de informações entre falante e ouvinte.

Por fim, perguntas meditativas (cf. (16)) funcionam como expressão de dúvidas e pensamentos do falante, isto é, são casos em que o falante assume desconhecer uma informação (-s) e pressupõe que o ouvinte também a desconheça (-id); nesses casos, as interrogativas não requerem uma resposta, e o falante apenas coloca o ouvinte como testemunha de seus pensamentos e devaneios. Assim, no Nível Interpessoal, o constituinte interrogativo figura como um Subato Referencial marcado pelo operador (-id, -s R).

(16) a Beto não levou o livro porque não quis, está pouco ligando para ela. Mais uma vez Ricardina sorriu, não fez comentários. $O$ que teria de tão especial esse livreco? Comecei a folheá-lo pelo fim e só então me dei conta de que o livro era escrito em espanhol. (19:Fic:Br:Gattai:Cronica)

NI: $\left(\mathrm{A}_{1}\right.$ : $\left[\left(\mathrm{F}_{1}\right.\right.$ : INT $\left.\left(\mathrm{F}_{1}\right)\right)\left(\mathrm{P}_{1}\right)_{\mathrm{S}}\left(\mathrm{P}_{2}\right)_{\mathrm{A}}\left(\mathrm{C}_{1}\right.$ : [(+id, -s $\mathbf{R}_{1}$ : o que $\left.\left(\mathbf{R}_{1}\right)_{\mathrm{Foc}}\right)\left(\mathrm{T}_{1}\right.$ : teria $\left.\left(\mathrm{T}_{1}\right)\right)\left(\mathrm{T}_{2}\right.$ : tão especial $\left.\left(T_{2}\right)\right)\left(R_{2}\right.$ : esse livreco $\left.\left.\left.\left.\left(R_{2}\right)\right)\right]\left(C_{1}\right)\right]\left(A_{1}\right)\right)$

NM: $\left(\mathrm{Cl}_{1}\right.$ : $\left[\left(\mathbf{N p}_{1}\right.\right.$ : o que $\left.\left(\mathbf{N p}_{1}\right)\right)\left(\mathrm{Vp}_{1}\right.$ : teria $\left.\left(\mathrm{Vp}_{1}\right)\right)\left(\mathrm{Adpp}_{1}\right.$ : de tão especial $\left.\left(\mathrm{Adpp}_{1}\right)\right)$ $\left(\mathrm{Np}_{2}\right.$ : esse livreco $\left.\left.\left.\left(\mathrm{Np}_{2}\right)\right)\right]\left(\mathrm{Cl}_{1}\right)\right)$

\begin{tabular}{|c|c|c|c|}
\hline $\mathbf{P}^{\mathrm{I}}$ & $\mathrm{P}^{\mathrm{M}}$ & $\mathrm{P}^{\mathrm{M}+1}$ & $\mathrm{P}^{\mathrm{F}}$ \\
\hline o que & teria & de tão especial & esse livreco \\
\hline
\end{tabular}


b Quando a mensagem de "missão imediata” chegou à mineradora, eram três e vinte. Esses pés-de-poeira estão malucos, negão - disse o Dr. Banto para seu companheiro Tiago. - Eles estão pensando o quê? Que isso aqui é cu-de-mãe-chica? Temos ainda que montar o guincho no Sapão, e não sei se vai dar tempo de cumprir a missão antes do pôr-do-sol. (19:Fic:Br:Cabral:Xambioa)

NI: $\left(\mathrm{A}_{1}\right.$ : $\left[\left(\mathrm{F}_{1}\right.\right.$ : INT $\left.\left(\mathrm{F}_{1}\right)\right)\left(\mathrm{P}_{1}\right)_{\mathrm{S}}\left(\mathrm{P}_{2}\right)_{\mathrm{A}}\left(\mathrm{C}_{1}\right.$ : $\left[\left(\mathrm{R}_{1}\right.\right.$ : eles $\left.\left(\mathrm{R}_{1}\right)_{\mathrm{Top}}\right)\left(\mathrm{T}_{1}\right.$ : estão pensando $\left.\left(\mathrm{T}_{1}\right)\right)$ (emph +id, -s $\mathbf{R}_{1}$ : o quê $\left.\left.\left.\left(\mathbf{R}_{1}\right)_{\mathrm{Foc}}\right)\right]\left(\mathrm{C}_{1}\right)\right]\left(\mathrm{A}_{1}\right)$ )

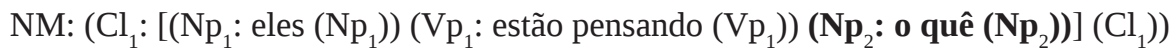

\begin{tabular}{|c|c|c|}
\hline $\mathrm{P}^{\mathrm{I}}$ & $\mathrm{P}^{\mathrm{M}}$ & $\mathbf{P}^{\mathrm{F}}$ \\
\hline eles & estão pensando & o quê? \\
\hline
\end{tabular}

Em (16a), a passagem traz um momento de reflexão particular do narrador, que expõe um de seus questionamentos (sobre o conteúdo do livro), sem esperar qualquer tipo de resposta; já em (16b), o falante se questiona sobre o quê estariam pensando os pés-de-poeira ao ordenar uma missão imediata; nota-se que se trata apenas de uma reflexão que parte do falante, sem esperar por resposta, nem a ter. Assim, em (16), a informação sob interrogação está ausente para ambos os participantes da interação, ou seja, é não específica (-s) e não identificável (-id). Esse tipo de pergunta coloca o ouvinte no papel de testemunha das dúvidas e/ou inquietações colocadas pelo falante na interação.

As três possíveis combinações do operador de identificabilidade/especificidade aplicadas ao constituinte interrogativo revelam, no geral, que a informação requerida ou interrogada não faz parte da informação pragmática de, pelo menos, um dos participantes da interação, ou melhor, o constituinte interrogativo o que/o quê codifica a ausência de uma informação no estado mental de pelo menos um dos participantes da interação verbal. Isso demonstra que o constituinte interrogativo corresponde, em termos comunicativos, a uma informação nova (cf. CHAFE, 1976) e, consequentemente, a uma informação focal, já que, conforme Hannay (1983), sinaliza a diferença entre a informação pragmática do falante e do ouvinte. Assim, no Nível Interpessoal, é atribuída, a esse Subato Referencial, a função pragmática Foco (Foc), o que mobiliza sua disposição nas margens da oração, inicial ou final.

Essa dupla disposição do constituinte interrogativo não é arbitrária, mas é motivada por estratégias coordenadas pelo falante de modo a melhor atender seus propósitos comunicativos em relação ao ouvinte. Defende-se, aqui, que essa dupla ordenação esteja associada ao que Downing (1995) chama de marcação de afeto: a ordem do constituinte interrogativo está a serviço do modo como o falante modela sua mensagem para ganhar, de alguma maneira, a atenção do ouvinte.

Quando em posição inicial na sentença (em $\mathrm{P}^{\mathrm{I}}$ ), como nas ocorrências em (14a), (15a) e (16a), o constituinte interrogativo é o ponto de partida para a interrogação ali colocada: em (14a), por exemplo, a pergunta prototípica parte do referente sobre o qual recai o pedido de informação; já em (15a), a pergunta retórica tem, como ponto de partida, a porção referencial que, na sequência, é assertada pelo próprio falante; por fim, em (16a), o referente que sinaliza a dúvida a ser exposta pela pergunta meditativa é seu ponto de partida. Assim, a posição inicial do constituinte interrogativo em (14a), (15a) e (16a) representa uma seleção estratégica, por 
parte do falante, em iniciar sua pergunta pela informação nova. Trata-se, então, da aplicação da função pragmática Foco ao Subato Referencial ( $\left.\mathrm{R}_{\mathrm{Foc}}\right)$.

Por outro lado, quando em posição final na sentença (em $\mathrm{P}^{\mathrm{F}}$ ), como nas ocorrências em (14b), (15b) e (16b), o constituinte interrogativo não mais é o ponto de partida para a pergunta, mas representa a informação para a qual o falante deseja chamar a atenção do ouvinte. Conforme assinala Moutaouakil (2011), trata-se de uma estratégia de intensificação de uma peça de informação (do Subato Referencial interrogativo, no caso) vinculada ao modo mais energético com que se apresenta essa determinada peça de informação.

Observa-se, portanto, que a posição final do constituinte interrogativo está articulada ao que Komen (2013) compreende por proeminência enfática: segundo o autor (KOMEN, 2013, p. 40), os marcadores de proeminência enfática podem expressar fortes sentimentos em relação a um item ou, também, indicar que o que se segue é inesperado. Assim, o constituinte interrogativo, ao final da sentença interrogativa, decorre de uma necessidade do falante em reforçar a sua pergunta, salientando e dando maior destaque ao Subato Referencial que, naquela interação, evoca a informação ausente. Assim, em (14b), (15b) e (16b), além da função pragmática Foco, atribui-se, ao Subato Referencial interrogativo, um operador de ênfase (emph $\mathrm{R}_{\mathrm{Foc}}$ ).

Retomando mais centralmente os casos de perguntas típicas, nota-se que ambas as interrogativas em (14) contêm um Conteúdo Comunicado (C) composto por um Subato Referencial focal $\left(\mathrm{R}_{\mathrm{Foc}}\right)$, o constituinte interrogativo, e um Subato Referencial tópico $\left(\mathrm{R}_{\mathrm{Top}}\right)$, o pronome você, sujeito do verbo da oração. A diferença entre elas recai na articulação pragmática desse conteúdo, o que se codifica pela ordem assumida pelos constituintes no interior da oração: em (14a), o ponto de partida é o Foco da sentença, posicionado em $\mathrm{P}^{\mathrm{I}}$, e o sujeito você, enquanto Tópico, posiciona-se numa posição relativa a $\mathrm{P}^{\mathrm{I}}$, especificamente em $\mathrm{P}^{\mathrm{I}+1}$; em (14b), por outro lado, o ponto de partida da pergunta é o Tópico da sentença, posicionado em $\mathrm{P}^{\mathrm{I}}$, e o constituinte interrogativo ocupa a posição final $\left(\mathrm{P}^{\mathrm{F}}\right)$, o que lhe garante maior proeminência comunicativa.

Em suma, a conclusão central desta seção é que o constituinte interrogativo corresponde, independente de sua ordenação, a uma informação focal dentro do Ato Interrogativo. Sua linearização em posição final assinala, além disso, ênfase, numa estratégia do falante em destacar o referente sob interrogação e, assim, direcionar, com maior apelo e reforço, a atenção do ouvinte para essa informação.

Outros meios, no interior das Interrogativas-Qu, podem ser mobilizados para enfatizar o constituinte interrogativo, como a construção-é que (cf. (17a)) e a construção-que (cf. (17b)). Essas construções só se aplicam ao constituinte interrogativo quando este se encontra em posição inicial, o que ajuda a corroborar a consideração de que, quando em posição final, o constituinte interrogativo carrega, além de Foco, a propriedade de ênfase.

(17) a Acho que vou fazer uma festinha aqui, com os meus companheiros. Então o que é que vai acontecer? Vai ser uma velharia do cão. (19Or:Br:Intrv:ISP)

NI: $\left(\mathrm{A}_{1}\right.$ : $\left[\left(\mathrm{F}_{1}\right.\right.$ : INT $\left.\left(\mathrm{F}_{1}\right)\right)\left(\mathrm{P}_{1}\right)_{\mathrm{S}}\left(\mathrm{P}_{2}\right)_{\mathrm{A}}\left(\mathrm{C}_{1}\right.$ : [(emph +id, -s $\mathbf{R}_{1}$ : o que $\left.\left(\mathbf{R}_{1}\right)_{\mathrm{Foc}}\right)\left(\mathrm{T}_{1}\right.$ : vai acontecer $\left.\left.\left.\left.\left(\mathrm{T}_{1}\right)\right)\right]\left(\mathrm{C}_{1}\right)\right]\left(\mathrm{A}_{1}\right)\right)$

NM: $\left(\mathrm{Cl}_{1}\right.$ : $\left[\left(\mathbf{N p}_{1}\right.\right.$ : o que $\left.\left(\mathbf{N p}_{1}\right)\right)\left(\mathbf{G w}_{1}\right.$ : é_que $\left.\left(\mathbf{G w}_{1}\right)\right)\left(\mathrm{Vp}_{1}\right.$ : vai acontecer $\left.\left.\left.\left(\mathrm{Vp}_{1}\right)\right)\right]\left(\mathrm{Cl}_{1}\right)\right)$

\begin{tabular}{|c|c|c|}
\hline $\mathbf{P}^{\mathrm{I}}$ & $\mathbf{P}^{\mathrm{I}+1}$ & $\mathrm{P}^{\mathrm{M}}$ \\
\hline o que & é que & vai acontecer \\
\hline
\end{tabular}


b Ninguém vai lembrar desse cara... o que que ele fez? Nada. (bestiario.com.br)

NI: $\left(\mathrm{A}_{1}\right.$ : [( $\mathrm{F}_{1}$ : INT $\left.\left(\mathrm{F}_{1}\right)\right)\left(\mathrm{P}_{1}\right)_{\mathrm{S}}\left(\mathrm{P}_{2}\right)_{\mathrm{A}}\left(\mathrm{C}_{1}\right.$ : [(emph +id, -s $\mathbf{R}_{1}$ : o que $\left.\left(\mathbf{R}_{1}\right)_{\mathrm{Foc}}\right)\left(\mathrm{R}_{2}\right.$ : ele $\left.\left(\mathrm{R}_{2}\right)\right)$ $\left(\mathrm{T}_{1}:\right.$ fez $\left.\left.\left.\left.\left(\mathrm{T}_{1}\right)\right)\right]\left(\mathrm{C}_{1}\right)\right]\left(\mathrm{A}_{1}\right)\right)$

NM: $\left(\mathrm{Cl}_{1}\right.$ : [( $\mathbf{N p}_{1}$ : o quê $\left.\left(\mathbf{N p}_{1}\right)\right)\left(\mathbf{G w}_{1}\right.$ : que $\left.\left(\mathbf{G w}_{1}\right)\right)\left(\mathrm{Np}_{2}\right.$ : ele $\left.\left(\mathrm{Np}_{2}\right)\right)\left(\mathrm{Vp}_{1}\right.$ : fez $\left.\left.\left(\mathrm{Vp}_{1}\right)\right)\right]$ $\left.\left(\mathrm{Cl}_{1}\right)\right)$

\begin{tabular}{|c|c|c|c|}
\hline $\mathbf{P}^{\mathrm{I}}$ & $\mathbf{P}^{\mathrm{I}+1}$ & $\mathrm{P}^{\mathrm{I}+2}$ & $\mathrm{P}^{\mathrm{M}}$ \\
\hline o que & que & ele & fez \\
\hline
\end{tabular}

\section{A ORDEM DE AINDA EM CONSTRUÇÕES COMPARATIVAS}

Esta última seção expande alguns resultados apresentados em Fontes (2016) ao abordar o uso do item ainda em construções comparativas de desigualdade formadas pelos quantificadores mais e menos (cf. (18); (19)).

(18) a Guida era assim como Lídia; quer dizer, mais bonita ainda do que Lídia, mas as duas se pareciam naquele tipo de amazona. (19:Fic:Br:Rodriguez:Destino)

NI: (emph $T_{1}$ : bonita $\left(\mathrm{T}_{1}\right)$ : $\left(\mathrm{T}_{2}\right.$ : mais $\left.\left.\left(\mathrm{T}_{2}\right)\right)\left(\mathrm{T}_{1}\right)\right)$

NR: $\left(f_{1}\right.$ : bonita ${ }_{\text {Adj }}\left(f_{1}\right):\left(f_{2}:\right.$ mais $\left.\left._{\text {Adv }}\left(f_{2}\right)\right)\left(f_{1}\right)\right)$

NM: $\left(\right.$ Adpp $_{1}$ : [(Advw $:$ mais $\left.\left(\operatorname{Advw}_{1}\right)\right)\left(\operatorname{Adjw}_{1}\right.$ : bonita $\left.\left(\mathrm{Adw}_{1}\right)\right)\left(\mathrm{Gw}_{1}\right.$ : $\left.\left.\operatorname{ainda}_{\text {Part }}\left(\mathrm{Gw}_{1}\right)\right)\right]$ $\left.\left(\operatorname{Adpp}_{1}\right)\right)$

\begin{tabular}{|c|c|c|}
\hline $\mathrm{P}^{\mathrm{I}}$ & $\mathrm{P}^{\mathrm{M}}$ & $\mathrm{P}^{\mathrm{F}}$ \\
\hline mais & bonita & ainda \\
\hline
\end{tabular}

b Só que em vez de continuar morto, Arandir levantou-se e caminhou para outro praticável mais atrás, um pouco mais alto. Lá, inteiramente nu, estava deitado outro rapaz ainda mais musculoso que ele, o rosto voltado para o fundo do palco. (19:Fic:Br:Abreu:Onde)

NI: $\left(\mathrm{T}_{1}\right.$ : musculoso $\left(\mathrm{T}_{1}\right)$ : ( ${ }^{\text {degree }}$ emph $\mathrm{T}_{2}$ : mais $\left.\left.\left(\mathrm{T}_{2}\right)\right)\left(\mathrm{T}_{1}\right)\right)$

NR: $\left(f_{1}:\right.$ musculoso $_{\text {Adj }}\left(f_{1}\right):\left(f_{2}:\right.$ mais $\left.\left._{\text {Adv }}\left(f_{2}\right)\right)\left(f_{1}\right)\right)$

NM: $\left(\operatorname{Adpp}_{1}\right.$ : $\left[\left(\mathrm{Gw}_{1}\right.\right.$ : ainda $\left._{\text {Part }}\left(\mathrm{Gw}_{1}\right)\right)\left(\operatorname{Advw}_{1}\right.$ : mais $\left.\left(\mathrm{Advw}_{1}\right)\right)\left(\mathrm{Adjw}_{1}\right.$ : musculoso $\left.\left.\left.\left(\operatorname{Adw}_{1}\right)\right)\right]\left(\operatorname{Adpp}_{1}\right)\right)$

\begin{tabular}{|c|c|c|}
\hline $\mathrm{P}^{\mathrm{I}}$ & $\mathrm{P}^{\mathrm{I}+1}$ & $\mathrm{P}^{\mathrm{M}}$ \\
\hline ainda & mais & musculoso \\
\hline
\end{tabular}

Em (18), a quantificação expressa pelo advérbio de grau mais recai sobre os adjetivos bonita e musculoso, o que, em (18a), situa Guida num grau superior de beleza em relação a Lídia, e, no caso de (18b), coloca outro rapaz num patamar mais elevado, em termos de ser musculoso, em comparação a Arandir. O uso de ainda, conforme Neves e Dall'Aglio-Hattnher (2002, p. 169), pode ser encarado como mecanismo de valorização da comparação de superioridade ali estabelecida pela palavra de grau mais. 
a Sem nada confessar a ninguém, nem a si próprio, pois que se considerava superior a querelas desse tipo, sentiu um pico de ciúmes, um amargor de traição. ao mesmo tempo, e de forma ainda mais ignorada, pois que menos digno ainda acharia tal sentimento, experimentou também um travo de alívio (19:Fic:Pt:Barreno:Ilhas)

NI: (emph $T_{1}$ : provável $\left(\mathrm{T}_{1}\right)$ : $\left(\mathrm{T}_{2}\right.$ : menos $\left.\left.\left(\mathrm{T}_{2}\right)\right)\left(\mathrm{T}_{1}\right)\right)$

NR: $\left(f_{1}: \operatorname{digno}_{\text {Adj }}\left(f_{1}\right):\left(f_{2}: \operatorname{menos}_{\text {Adv }}\left(f_{2}\right)\right)\left(f_{1}\right)\right)$

NM: $\left(\operatorname{Adpp}_{1}\right.$ : [(Advw ${ }_{1}$ : menos $\left.\left(\operatorname{Advw}_{1}\right)\right)\left(\operatorname{Adjw}_{1}\right.$ : digno $\left.\left(\operatorname{Adw}_{1}\right)\right)\left(\mathrm{Gw}_{1}\right.$ : ainda part $\left.\left.\left.\left(\mathrm{Gw}_{1}\right)\right)\right]\left(\mathrm{Adpp}_{1}\right)\right)$

\begin{tabular}{|c|c|c|}
\hline $\mathrm{P}^{\mathrm{I}}$ & $\mathrm{P}^{\mathrm{M}}$ & $\mathrm{P}^{\mathrm{F}}$ \\
\hline menos & digno & ainda \\
\hline
\end{tabular}

b Fez o inverso: depois de longa inatividade em Monte Santo, a expedição partiu ainda menos aparelhada do que quando ali chegara quinze dias antes, abandonando, ainda uma vez, parte dos restos de um trem de guerra já muitíssimo reduzido. (19:Fic:Br:Cunha:Sertoes)

NI: ( $\mathrm{T}_{1}$ : aparelhada $\left(\mathrm{T}_{1}\right)$ : (degree emph $\mathrm{T}_{2}$ : menos $\left.\left.\left(\mathrm{T}_{2}\right)\right)\left(\mathrm{T}_{1}\right)\right)$

NR: $\left(f_{1}\right.$ : aparelhada $_{\text {Adj }}\left(f_{1}\right):\left(f_{2}:\right.$ menos $\left.\left._{\text {Adv }}\left(f_{2}\right)\right)\left(f_{1}\right)\right)$

NM: (Adpp ${ }_{1}$ : $\left[\left(\mathrm{Gw}_{1}\right.\right.$ : ainda $\left._{\text {Part }_{1}}\left(\mathrm{Gw}_{1}\right)\right)\left(\operatorname{Advw}_{1}\right.$ : menos $\left.\left(\mathrm{Advw}_{1}\right)\right)\left(\right.$ Adjw $_{1}$ : aparelhada $\left.\left.\left.\left(\operatorname{Adw}_{1}\right)\right)\right]\left(\operatorname{Adpp}_{1}\right)\right)$

\begin{tabular}{|c|c|c|}
\hline $\mathrm{P}^{\mathrm{I}}$ & $\mathrm{P}^{\mathrm{I}+1}$ & $\mathrm{P}^{\mathrm{M}}$ \\
\hline ainda & menos & aparelhada \\
\hline
\end{tabular}

Já em (19), a quantificação sobre os adjetivos provável e aparelhada é operada pelo graduador menos: no caso de (19a), situa-se o grau de dignidade do sentimento em uma posição inferior às querelas anteriormente citadas; já em (19b), o grau de aparelhamento da expedição atual é inferior quando comparado ao da expedição de quinze dias antes. Assim como em (18), ainda opera, em (19), certo reforço ou valorização sobre a comparação de inferioridade ali estabelecida pela palavra de grau menos.

A comparação de desigualdade em (18) e (19) se estabelece, no Nível Representacional, a partir da modificação quantificacional de Propriedades Adjetivais ( $\mathrm{f}_{\text {Adj }}$ ) por meio de advérbios de grau como mais ou menos, que podem ser analisadas como Propriedades Adverbiais $\left(\mathrm{f}_{\text {Adv }}\right.$ ). O uso de ainda, ao salientar comunicativamente a comparação estabelecida no enunciado, é captado no Nível Interpessoal, enquanto estratégia de natureza pragmática.

Em (18a) e (19a), ainda escopa toda a comparação ali construída, isto é, a combinação entre os dois Subatos Atributivos ( $\mathrm{T})$ : o que corresponde ao adjetivo $\left(\mathrm{T}_{1}\right)$ e o que corresponde ao advérbio de grau $\left(\mathrm{T}_{2}\right)$. Já em (18b) e (19b), o escopo de ainda se restringe a um dos elementos da comparação, especificamente ao Subato Atributivo que corresponde à palavra de grau $\left(\mathrm{T}_{2}\right)$.

Essa diferença de escopo se reflete na ordenação assumida por ainda no interior do Sintagma Adjetivo (Adjp), no Nível Morfossintático. Em (18a) e (19a), ainda, uma Partícula Gramatical $(\mathrm{Gw})$, posiciona-se ao final do Sintagma Adjetival, na posição absoluta final $\left(\mathrm{P}^{\mathrm{F}}\right)$, à direita do núcleo do sintagma, isto é, da Palavra Adjetival (Adjw), alocada na posição absoluta medial $\left(\mathrm{P}^{\mathrm{M}}\right)$; na posição absoluta inicial $\left(\mathrm{P}^{\mathrm{I}}\right)$, encontra-se a palavra de grau mais ou menos, 
uma Palavra Adverbial (Advw). Em (18b) e (19b), por outro lado, esse padrão morfossintático é um pouco distinto: ainda se posiciona no início do Sintagma Adjetival, na posição absoluta $\mathrm{P}^{\mathrm{I}}$, adjacente à palavra de grau mais, que passa a ocupar uma posição relativa a $\mathrm{P}^{\mathrm{I}}$, no caso a posição $\mathrm{P}^{\mathrm{I}+1}$; o núcleo do sintagma, a Palavra Adjetival, ocupa a posição absoluta medial $\left(\mathrm{P}^{\mathrm{M}}\right)$.

Essa “variabilidade” na ordenação de ainda em construções comparativas de desigualdade não se dá somente por conta de diferenças em termos de relações de escopo, mas também por conta de diferenças quanto às estratégias pragmáticas próprias à intenção comunicativa do falante ao modelar sua mensagem.

Com base em Kohler (2006), pode-se distinguir funcionalmente as ocorrências em (18) e (19) da seguinte maneira:

(i) $\quad$ Em (18a) e (19a), casos em que a ordenação de ainda ao final do Sintagma Adjetivo revela seu escopo sobre toda a comparação, isto é, sobre a combinação entre a noção comparada (expressa pelo adjetivo) e o quantificador (a palavra de grau), trata-se de uma proeminência especial conferida à comparação e, assim, ainda apenas salienta e destaca a comparação, chamando a atenção do ouvinte para ela. Ainda corresponde então a um operador de ênfase (emph);

(ii) Já em (18b) e (19b), casos em que a ordenação de ainda em $\mathrm{P}^{\mathrm{I}}$ é contígua e adjacente à palavra de grau, posicionada em $\mathrm{P}^{\mathrm{I}+1}$, refletindo seu escopo pontual sobre o Subato Atributivo que corresponde à palavra de grau, trata-se de um reforço especial conferido à comparação, de modo que ainda potencializa e amplifica o significado graduador expresso pelas palavras mais e menos. Assim, ainda corresponde ao que aqui se denomina de operador de ênfase graduadora ( ${ }^{\text {degree }}$ emph).

Silva (2014, p. 44), ao tratar de construções comparativas, prevê que o grau veiculado por mais e menos pode vir acrescido "de outros elementos graduadores, numa espécie de reforço/ ênfase a uma noção já graduada, amplificando-a/elevando-a ou reduzindo-a/rebaixando-a ainda mais”. A proposta aqui é precisar esse tipo de afirmação, prevendo, então, que além da ênfase propriamente dita, em termos de saliência e proeminência comunicativa, pode-se aplicar à estrutura comparativa um subtipo de ênfase, a ênfase graduadora, que potencializa e amplifica a desigualdade (ou o grau desigual) expressa e estabelecida pelo quantificador mais e menos. No caso de ainda, essa distinção se opera por meio da ordem que assume no interior do Sintagma Adjetivo: quando ao final do sintagma, ainda é um operador de ênfase; quando adjacente à palavra de grau (no início do sintagma), ainda é um operador de ênfase graduadora.

Essa distinção se aplica sistematicamente a casos de comparação de desigualdade com substantivos (cf. (20)) e verbos (cf. (21)).

(20) a e não tem medo de não estar seguindo as regras do teatro e tenho menos medo ainda em ter uma identidade muito clara, ter cara própria, e fugir dos padrões a que os atores são lobotomizados (19N:Br:SP)

NI: (emph $\mathrm{R}_{1}$ : medo $\left(\mathrm{T}_{1}\right)$ : $\left(\mathrm{T}_{2}\right.$ : menos $\left.\left.\left(\mathrm{T}_{2}\right)\right)\left(\mathrm{T}_{1}\right)\right)$

NR: $\left(f_{1}:\right.$ medo $_{\mathrm{N}}\left(f_{1}\right):\left(f_{2}:\right.$ menos $\left.\left._{\text {Adv }}\left(f_{2}\right)\right)\left(f_{1}\right)\right)$

NM: $\left(\mathrm{Np}_{1}\right.$ : [(Advw $\mathrm{Ad}_{1}$ menos $\left.\left(\mathrm{Advw}_{1}\right)\right)\left(\mathrm{Nw}_{1}\right.$ : medo $\left.\left(\mathrm{Nw}_{1}\right)\right)\left(\mathbf{G w}_{1}\right.$ : ainda $\left.\left.{ }_{\text {Part }}\left(\mathbf{G w}_{1}\right)\right)\right]$ $\left.\left(\mathrm{Np}_{1}\right)\right)$

\begin{tabular}{|c|c|c|}
\hline $\mathrm{P}^{\mathrm{I}}$ & $\mathrm{P}^{\mathrm{M}}$ & $\mathbf{P}^{\mathrm{F}}$ \\
\hline menos & medo & ainda \\
\hline
\end{tabular}


b Quando se ria, a água jorrava das fontes com mais força ainda, e o sol espreitava por entre as nuvens para se rir também. (19:Fic:Pt:Ferro:Tudo)

NI: (emph $R_{1}$ : força $\left(T_{1}\right)$ : $\left(T_{2}\right.$ : mais $\left.\left.\left(T_{2}\right)\right)\left(T_{1}\right)\right)$

$N R$ : $\left(f_{1}\right.$ : força ${ }_{N}\left(f_{1}\right):\left(f_{2}:\right.$ mais $\left.\left._{\text {Adv }}\left(f_{2}\right)\right)\left(f_{1}\right)\right)$

NM: $\left(\mathrm{Np}_{1}\right.$ : [(Advw ${ }_{1}$ : mais $\left.\left(\mathrm{Advw}_{1}\right)\right)\left(\mathrm{Nw}_{1}\right.$ : força $\left.\left(\mathrm{Nw}_{1}\right)\right)\left(\mathbf{G w}_{1}\right.$ : ainda Part $\left.\left.\left.\left(\mathbf{G w}_{1}\right)\right)\right]\left(\mathrm{Np}_{1}\right)\right)$

\begin{tabular}{|c|c|c|}
\hline $\mathrm{P}^{\mathrm{I}}$ & $\mathrm{P}^{\mathrm{M}}$ & $\mathbf{P}^{\mathrm{F}}$ \\
\hline mais & força & ainda \\
\hline
\end{tabular}

c A questão só não é dolorosa em Portugal porque em Portugal nunca houve grandes universidades - - e houve ainda menos excepções. O espírito de dissensão e debate violento da Sorbonne do século XIII pode hoje mais facilmente encontrar-se num community college do Oklahoma que na sua sucessora parisiense. (19Or:Pt:Intrv:Web)

NI: $\left(\mathrm{R}_{1}\right.$ : excepções $\left(\mathrm{T}_{1}\right)$ : ( ${ }^{\text {degree }}$ emph $\mathrm{T}_{2}$ : menos $\left.\left.\left(\mathrm{T}_{2}\right)\right)\left(\mathrm{T}_{1}\right)\right)$

NR: $\left(f_{1}\right.$ : excepções $\left.{ }_{N}\left(f_{1}\right):\left(f_{2}: \operatorname{menos}_{\text {Adv }}\left(f_{2}\right)\right)\left(f_{1}\right)\right)$

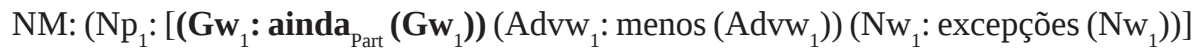
$\left.\left(\mathrm{Np}_{1}\right)\right)$

\begin{tabular}{|c|c|c|}
\hline $\mathbf{P}^{\mathrm{I}}$ & $\mathrm{P}^{\mathrm{I}+1}$ & $\mathrm{P}^{\mathrm{M}}$ \\
\hline ainda & menos & excepções \\
\hline
\end{tabular}

d Tentara ajudar a irmã no brechó, mas não conseguira se concentrar nas tarefas mais simples. Quando algum comprador fazia uma pergunta, levava algum tempo até sintonizar com o som da voz; para responder à pergunta, levava ainda mais tempo. Achou melhor ficar no quarto. (19:Fic:Br:Garcia:Silencio)

NI: $\left(\mathrm{R}_{1}\right.$ : tempo $\left(\mathrm{T}_{1}\right)$ : (degree emph $\mathrm{T}_{2}$ : mais $\left.\left.\left(\mathrm{T}_{2}\right)\right)\left(\mathrm{T}_{1}\right)\right)$

NR: $\left(f_{1}: \operatorname{tempo}_{\mathrm{N}}\left(\mathrm{f}_{1}\right):\left(\mathrm{f}_{2}:\right.\right.$ menos $\left.\left._{\text {Adv }}\left(\mathrm{f}_{2}\right)\right)\left(\mathrm{f}_{1}\right)\right)$

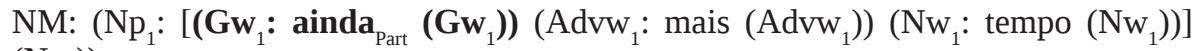
$\left.\left(\mathrm{Np}_{1}\right)\right)$

\begin{tabular}{|c|c|c|}
\hline $\mathbf{P}^{\mathrm{I}}$ & $\mathrm{P}^{\mathrm{I}+1}$ & $\mathrm{P}^{\mathrm{M}}$ \\
\hline ainda & mais & tempo \\
\hline
\end{tabular}

Em (20), a quantificação expressa pelos advérbios menos e mais recai sobre substantivos, ou seja, há uma relação de modificação, no Nível Representacional, entre a palavra de grau e o substantivo, uma Propriedade Lexical (f). Já no Nível Interpessoal, os substantivos correspondem a Subatos Referenciais, e as palavras de grau a Subatos Atributivos. Em (20a-b), ainda escopa o domínio focal da comparação, isto é, o modificador que sinaliza a dimensão da comparação (mais) e o foco da comparação (as propriedades designadas pelos substantivos), reforçando e/ ou destacando esse domínio comparativo e, assim, funcionando como um operador de ênfase. Em (20c-d), por outro lado, o escopo de ainda recai somente sobre a palavra de grau e, enquanto operador de ênfase graduadora, amplifica ou potencializa a desigualdade ali estabelecida.

No Nível Morfossintático, isso se reflete em sua ordenação no interior do Sintagma Nominal (Np): enquanto, em (20a-b), ainda se posiciona ao final do sintagma, em $\mathrm{P}^{\mathrm{F}}$, à direita do núcleo nominal, posicionado em $\mathrm{P}^{\mathrm{M}}$, em (20c-d), ainda se posiciona no início do sintagma, em $\mathrm{P}^{\mathrm{I}}$, adjacente à palavra de grau, que ocupa uma posição relativa à de ainda, a posição $\mathrm{P}^{\mathrm{I}+1}$. 
(21) a Delfino não gostou da observação, mas não disse nada. Aliás, gostou menos ainda de ouvir Adriano exumar aquele apelido de Fininho (19:Fic:Br:Callado:Madona)

NI: (emph $\mathrm{T}_{1}$ : gostou $\left(\mathrm{T}_{1}\right):\left(\mathrm{T}_{2}\right.$ : menos $\left.\left.\left(\mathrm{T}_{2}\right)\right)\left(\mathrm{T}_{1}\right)\right)$

NR: $\left(\mathrm{f}_{1}: \operatorname{gostou}_{\mathrm{V}}\left(\mathrm{f}_{1}\right):\left(\mathrm{f}_{2}: \operatorname{menos}_{\text {Adv }}\left(\mathrm{f}_{2}\right)\right)\left(\mathrm{f}_{1}\right)\right)$

NM: $\left(\mathrm{Vp}_{1}\right.$ : $\left[\left(\mathrm{Vw}_{1}\right.\right.$ : gostou $\left.\left(\mathrm{Vw}_{1}\right)\right)\left(\mathrm{Advw}_{1}\right.$ : menos $\left.\left(\mathrm{Advw}_{1}\right)\right)\left(\mathrm{Gw}_{1}\right.$ : ainda Part $\left.\left.\left(\mathrm{Gw}_{1}\right)\right)\right]$ $\left.\left(\mathrm{Vp}_{1}\right)\right)$

\begin{tabular}{|c|c|c|}
\hline $\mathrm{P}^{\mathrm{M}}$ & $\mathrm{P}^{\mathrm{F}-1}$ & $\mathbf{P}^{\mathrm{F}}$ \\
\hline gostou & menos & ainda \\
\hline
\end{tabular}

b Os olhos de Maurício não tinham mais aquela doçura intensa e perturbadora; estavam frios, lúcidos e frios, exprimiam uma maldade, uma determinação tal que Leninha recuou mais ainda. (19:Fic:Br:Rodriguez:Destino)

NI: (emph $\mathrm{T}_{1}$ : recuou $\left(\mathrm{T}_{1}\right):\left(\mathrm{T}_{2}\right.$ : mais $\left.\left.\left(\mathrm{T}_{2}\right)\right)\left(\mathrm{T}_{1}\right)\right)$

NR: $\left(f_{1}: \operatorname{recuou}_{v}\left(f_{1}\right):\left(f_{2}:\right.\right.$ mais $\left.\left._{\text {Adv }}\left(f_{2}\right)\right)\left(f_{1}\right)\right)$

NM: $\left(\mathrm{Vp}_{1}\right.$ : [(Vw $\mathrm{Vw}_{1}$ recuou $\left.\left(\mathrm{Vw}_{1}\right)\right)\left(\mathrm{Advw}_{1}\right.$ : mais $\left.\left(\operatorname{Advw}_{1}\right)\right)\left(\mathrm{Gw}_{1}\right.$ : ainda Part $\left.\left.\left(\mathrm{Gw}_{1}\right)\right)\right]$ $\left.\left(\mathrm{Vp}_{1}\right)\right)$

\begin{tabular}{|c|c|c|}
\hline $\mathrm{P}^{\mathrm{M}}$ & $\mathrm{P}^{\mathrm{F}-1}$ & $\mathbf{P}^{\mathrm{F}}$ \\
\hline recuou & mais & ainda \\
\hline
\end{tabular}

c Se hoje o brasileiro não gosta de pagar imposto, naquela época gostava ainda menos. (19Or:Br:Intrv:ISP)

NI: $\left(\mathrm{T}_{1}\right.$ : gostava $\left(\mathrm{T}_{1}\right)$ : ( ${ }^{\text {degree }}$ emph $\mathrm{T}_{2}$ : menos $\left.\left.\left(\mathrm{T}_{2}\right)\right)\left(\mathrm{T}_{1}\right)\right)$

NR: $\left(f_{1}: \operatorname{gostava}_{\mathrm{V}}\left(\mathrm{f}_{1}\right):\left(\mathrm{f}_{2}: \operatorname{menos}_{\text {Adv }}\left(\mathrm{f}_{2}\right)\right)\left(\mathrm{f}_{1}\right)\right)$

NM: $\left(\mathrm{Vp}_{1}\right.$ : [(Vw $:$ gostava $\left.\left(\mathrm{Vw}_{1}\right)\right)\left(\mathrm{Gw}_{1}\right.$ : ainda $\left.\left.{ }_{\text {Part }}\left(\mathrm{Gw}_{1}\right)\right)\left(\mathrm{Advw}_{1}: \operatorname{menos}\left(\mathrm{Advw}_{1}\right)\right)\right]$ $\left.\left(\mathrm{Vp}_{1}\right)\right)$

\begin{tabular}{|c|c|c|}
\hline $\mathrm{P}^{\mathrm{M}}$ & $\mathbf{P}^{\mathrm{F}-1}$ & $\mathrm{P}^{\mathrm{F}}$ \\
\hline gostava & ainda & menos \\
\hline
\end{tabular}

d O estupro trata de uma situação limite de invasão da intimidade do outro, uma agressão em máximo grau e pode causar não só seríssimos problemas emocionais e psicológicos como danos físicos, doenças sérias e até uma gravidez, que complica ainda mais a situação da vítima. (19Ac:Br:Enc)

NI: $\left(\mathrm{T}_{1}\right.$ : complica $\left(\mathrm{T}_{1}\right)$ : $\left({ }^{\text {degree }}\right.$ emph $\mathrm{T}_{2}$ : mais $\left.\left.\left(\mathrm{T}_{2}\right)\right)\left(\mathrm{T}_{1}\right)\right)$

NR: $\left(\mathrm{f}_{1}\right.$ : complica $_{\mathrm{v}}\left(\mathrm{f}_{1}\right):\left(\mathrm{f}_{2}:\right.$ mais $\left.\left._{\text {Adv }}\left(\mathrm{f}_{2}\right)\right)\left(\mathrm{f}_{1}\right)\right)$

NM: $\left(\mathrm{Vp}_{1}\right.$ : [(Vw $\mathrm{Vw}_{1}$ complica $\left.\left(\mathrm{Vw}_{1}\right)\right)\left(\mathrm{Gw}_{1}\right.$ : $\left.\operatorname{ainda}_{\text {Part }}\left(\mathrm{Gw}_{1}\right)\right)\left(\mathrm{Advw}_{1}:\right.$ mais $\left.\left.\left(\mathrm{Advw}_{1}\right)\right)\right]$ $\left.\left(\mathrm{Vp}_{1}\right)\right)$

\begin{tabular}{|c|c|c|}
\hline $\mathrm{P}^{\mathrm{M}}$ & $\mathbf{P}^{\mathrm{F}-1}$ & $\mathrm{P}^{\mathrm{F}}$ \\
\hline complica & ainda & mais \\
\hline
\end{tabular}

Em (21), por outro lado, a quantificação expressa pelos advérbios menos e mais recai sobre verbos, ou seja, há uma relação de modificação, no Nível Representacional, entre a palavra de grau e a palavra verbal, uma Propriedade Lexical (f). No Nível Interpessoal, tanto verbo como 
as palavras de grau são Subatos Atributivos e ainda opera ênfase: em (21a-b), ainda é operador de ênfase, escopando o domínio focal da comparação, isto é, o modificador que sinaliza a dimensão da comparação (mais) e o foco da comparação (as propriedades designadas pelos verbos); já em (21c-d), ainda é operador de ênfase graduadora, com escopo sobre a palavra de grau.

No Nível Morfossintático, isso se reflete em sua ordenação no interior do Sintagma Verbal (Vp): enquanto, em (21a-b), ainda se posiciona ao final do sintagma, em $\mathrm{P}^{\mathrm{F}}$, em (21c-d), ainda se posiciona na adjacência entre a Palavra Verbal ( $\mathrm{Vw}$ ) e o advérbio de grau (Advw), ocupando uma posição relativa $\left(\mathrm{P}^{\mathrm{F}-1}\right)$ em relação à posição absoluta final $\left(\mathrm{P}^{\mathrm{F}}\right)$ da palavra de grau. É no caso específico de (21c-d) que se pode observar melhor a aplicação de ainda, operador de ênfase graduadora, sobre a palavra de grau menos/mais, já que sua ordenação na adjacência entre verbo e palavra de grau segue os princípios de integridade de domínio e de preservação de relação de escopo, mantendo o item ainda contíguo e justaposto ao elemento ao qual se aplica num nível superior.

Todos os casos aqui abordados revelam a necessidade de se especificar a operação de ênfase, prevendo um subtipo enfático, a ênfase graduadora. Assim, no que toca às comparações de desigualdade com menos/mais, a distinção, operada por ainda, entre ênfase propriamente dita e ênfase graduadora se marca pela ordem assumida pelo item no interior do sintagma comparativo.

\section{CONSIDERAÇÕES FINAIS}

Este artigo revela, centralmente, uma sistemática correlação, no interior do sistema linguístico do português, entre expressão de ênfase e ordem de palavras. Em relação aos casos aqui abordados, demonstra-se que:

(i) A ordenação final do constituinte interrogativo é uma estratégia do falante em destacá-lo e, assim, apelar para a atenção do ouvinte em direção a essa informação, o que, na GDF, captura-se pela aplicação de um operador de ênfase ao Subato Referencial interrogativo;

(ii) A ordenação de ainda no interior de construções comparativas de desigualdade instaura diferentes efeitos enfáticos: quando ao final do sintagma comparativo, é uma estratégia de saliência e de proeminência, o que, na GDF, captura-se pelo operador de ênfase; quando adjacente à palavra de grau - no início do sintagma adjetivo ou nominal ou entre verbo e palavra de grau -, ainda representa uma estratégia de potencialização da desigualdade ali estabelecida por mais ou menos, o que leva este trabalho a propor um novo (sub)tipo enfático na GDF: o operador de ênfase graduadora.

Em suma, este artigo, além de um exercício de análise funcionalmente orientada, oferece reflexões que contribuem não só para uma abordagem da ordem de palavras enquanto correlato de propriedades funcionais, mas também para uma compreensão da ênfase como operação de natureza pragmática/discursiva distinta de outras, como a focalização, o que é uma questão bastante peculiar e importante para o modelo da GDF. 


\section{REFERÊNCIAS}

BUTLER, C. S. Structure and function: a guide to three major structural-functional theories. Amsterdam: John Benjamins, 2003.

CHAFE, W. Giveness, contrastiveness, defineness, subjects and topics. In: LI, C. Subject and Topic. New York: Academic Press, 1976, p. 26-55.

DAVIES, M.; FERREIRA, M. Corpus do Português: 45 milhões de palavras, 1300s-1900s, 2006. Disponível online em http://www.corpusdoportugues.org.

DIK, S. C. The theory of functional grammar: the structure of the clause. Berlin/New Tork: Mouton de Gruyter, 1997a.

DIK, S. C. The theory of functional grammar: complex and derived structures. Berlin/New Tork: Mouton de Gruyter, 1997b.

DOWNING, P. Word order in discourse: By way of introduction. In: NOONAN, M; DOWNING, P. (Ed.). Word order in discourse. Amsterdam: John Benjamins, 1995, p. 1-28.

FONTES, M. G. As interrogativas de conteúdo na história do português brasileiro: uma abordagem discursivo-funcional. 2012. 180 f. Dissertação (Mestrado em Estudos Linguísticos). Universidade Estadual Paulista - Júlio de Mesquita Filho, campus de São José do Rio Preto, 2012a.

FONTES, M. G. Ordenação de constituintes em sentenças interrogativas do português brasileiro: uma visão diacrônica. Revista Estudos Linguísticos, São Paulo, n. 41 (1), p. 7489, 2012b.

FONTES, M. G. A distinção léxico-gramática na Gramática Discursivo-Funcional: uma proposta de implementação. 2016. 236f. Tese (Doutorado em Estudos Linguísticos). Universidade Estadual Paulista “Júlio de Mesquita Filho”, campus de São José do Rio Preto, 2016.

HANNAY, M. The focus function in functional grammar: questions of contrast and context. In: DIK, S. C. (Org.). Advances in functional grammar. Dordrecht: Foris, 1983, p. 207-223.

HENGEVELD, K.; MACKENZIE, J. L. Functional Discourse Grammar: a typologicallybased theory of language structure. Oxford: Oxford Press, 2008.

HENGEVELD, K.; MACKENZIE, J. L. Gramática Discursivo-Funcional. In: SOUZA, E. R. (Org.). Funcionalismo linguístico: novas tendências teóricas Tradução de Marize Mattos Dall’Aglio-Hattnher. São Paulo: Contexto, 2012, p. 43-82.

HERRING, S. C.; PAOLILLO, J. C. Focus position in SOV languages. In: NOONAN, M; DOWNING, P. (Ed.). Word order in discourse. Amsterdam: John Benjamins, 1995, p. 163-198.

KOHLER, K. J. What is emphasis and how is it coded? In: Proceedings of 3rd International Conference on Speech Prosody. Dresden. 2006. p. 748-751.

KOMEN, E. R. Finding Focus: a study of the historical development of focus in English. The Netherlands: LOT, 2013. 
NEVES, M. H. M.; DALL'AGLIO-HATTNHER, M. M. D. As construções comparativas. In: ABAURRE, M. B. M.; RODRIGUES, A. C. (Org.). Gramática do Português Falado: Novos estudos descritivos. v. 8. Campinas/SP: Editora da UNICAMP, 2002, p. 113-183.

PEZATTI, E. G. A ordem das palavras no português. São Paulo: Parábola, 2014.

SILVA, J. R. O grau em perspectiva: uma abordagem centrada no uso. São Paulo: Cortez, 2014.

Recebido em: jul. 2020.

Aceito em: nov. 2020. 